\title{
Exploring Self-Concept for Students with Emotional and/or Behavioral Disorders as They Transition from Elementary to Middle School and High School
}

\author{
Nicholas A. Gage ${ }^{1}$ and Kristin Lierheimer ${ }^{2}$ \\ ${ }^{1}$ Department of Educational Psychology, University of Connecticut, Storrs, CT 06269, USA \\ ${ }^{2}$ Department of Special Education, University of Missouri, Columbia, MO 65211, USA
}

Correspondence should be addressed to Nicholas A. Gage, gagenicholas@gmail.com

Received 26 August 2011; Revised 15 November 2011; Accepted 21 November 2011

Academic Editor: João A. Lopes

Copyright ( $) 2012$ N. A. Gage and K. Lierheimer. This is an open access article distributed under the Creative Commons Attribution License, which permits unrestricted use, distribution, and reproduction in any medium, provided the original work is properly cited.

\begin{abstract}
Although significant research has been conducted around assessment and intervention for students with emotional and/or behavioral disorders (EBDs), few have investigated specifically how students with EBD self-report on their academic and social competence, or self-concept. Using a national longitudinal database, this study explored how students with EBD reported their selfconcept in elementary school, how their reported self-concept changed as they transitioned to middle and high school, and, what factors influenced this change. Using latent growth modeling procedures, the study found that students with EBD reported high self-concept across time and that reported self-concept was most impacted by ethnicity $(\beta=-.174)$ and urbanicity $(\beta=-.113)$.
\end{abstract}

\section{Introduction}

Students with emotional and/or behavioral disorders (EBDs) present many challenges for schools, displaying elevated levels of problem behaviors resulting in increased placement in segregated settings [1] and bleak short- and longterm outcomes [2]. Longitudinal research shows troubling academic and behavioral trajectories for students with and at-risk for EBD, including that they maintain elevated levels of problem behaviors and academic deficits as they transition from elementary to middle and high school [3].

Targeted interventions have been identified as necessary to break the cycle of academic and behavioral deficits for students with EBD [4]. However, less research has focused on the role of self-reported self-concept and its relation to both problem behaviors and interventions targeting those behaviors [5]. Students with EBD are generally presented as unable to make or sustain healthy friendships and are isolated during their elementary years because of their behavior problems [6]. In U.S. schools, these students are identified for special education services based on the Emotional Disturbance disability category definition outlined as follows by the Individuals with Disabilities Education Act of 2004. (i) The term Emotional Disturbance means a condition exhibiting one or more of the following characteristics over a long period of time and to a marked degree that adversely affects a child's educational performance:

(a) an inability to learn which cannot be explained by intellectual, sensory, or health factors;

(b) an inability to build or maintain satisfactory interpersonal relationships with peers and teachers;

(c) inappropriate types of behavior or feelings under normal circumstances;

(d) a general pervasive mood of unhappiness or depression;

(e) a tendency to develop physical symptoms of fears associated with personal or school problems.

(ii) The term includes schizophrenia. The term does not apply to children who are socially maladjusted, unless it is determined that they have an emotional disturbance (CFR §300.7 (a) 9). 
Although this disability category includes a heterogeneous group of students with varying topographies and intensities of behaviors and difficulty making academic progress, they typically receive services alongside one another and are generally presented as a broad categorical milieu. Although research has examined characteristics of these students generally, there has been a paucity of research that has specifically examined how these students self-report in regards to their self-concept, or the cognitive appraisal of their academic, and social competence $[7,8]$.

1.1. Self-Concept. Within a developmental framework, students' self-concept is not static but is a fluid construct influenced by social interactions with peers and adults. Selfconcept is influenced by successes and failures in social and academic endeavors and is currently conceptualized as hierarchically structured and multidimensional $[9,10]$. Gecas [11] elaborated upon the distinction between the self and self-concept, defining "self" as a process of reflexivity from the dialectic between the "I" and "me", or the mediation of identity as we conceive it, and self-concept as a product of the reflexive activity of the "self" process. The work of Epstein [12] suggested that self-concept could be conceptualized as a theory a person holds about the self as an experience, functioning being in interaction with world.

Unlike self-concept, self-esteem is a self-evaluation; it is the affective, or emotional, aspect of self-concept [13]. However, self-concept and self-esteem are interrelated concepts with self-esteem serving a motivational role in meeting one's needs socially and academically [7]. For example, if students state that they have trouble making friends in school, a cognitive statement about their social competence, they will not likely be motivated to continue to try because low social self-esteem results from multiple failures. Two types of self-esteem have been distinguished within the literature related to motivation and self-concept: (1) self-esteem based on a sense of power, competence, or efficacy, and (2) self-esteem based on a sense of virtue or moral worth. Competency-based self-esteem is intimately related to effective performance and is associated with selfattribution, while virtue-based self-esteem is grounded in norms and values about conduct $[11,14]$. This distinction between sources of self-esteem is noted as they are related to self-concept; an individual's self-concept can include their cognitive belief about their competence (i.e., I can ask a question in class when I need to) and their values (i.e., I do not lie), but the evaluative appraisal of their self-concept is self-esteem.

\subsection{Psychological and Educational Theories of Self-Concept.} Research has examined the interrelationship between academic achievement and self-concept for students generally (see Huang [15] and [9] for complete reviews). Huang [15] examined the longitudinal relationship between selfconcept and academic achievement using a meta-analytic path analysis approach with 39 independent samples of general education students (mean $N$ of 1143 per study) from 32 studies, finding medium to large effect sizes between selfconcept and academic achievement. Results of the Huang study suggest that there is a $60 \%$ chance that a student with high self-concept will have high academic achievement and vice versa. These findings support the interrelationship among academic achievement and self-concept and suggest that targeted interventions may have concomitant effects on both constructs.

1.2.1. Self-Concept and Students with Disabilities. Gresham and MacMillan [16] examined the literature associated with self-concept and students with high-incidence disabilities and found a developing body of research in this area for students with learning disabilities and mild intellectual disabilities, but less for students with EBD. Research with students with learning disabilities (LDs) has shown mixed findings. Although students with learning disabilities typically exhibit lower academic self-concept [17, 18], findings of global self-concept have been divided, with earlier studies finding students with LD having significantly lower global self-esteem than students without disabilities [19], while later studies found no differences between students with LD and students without disabilities [20]. For students with EBD, a different pattern of self-concept has been found. Hoza et al. [21] examined self-concept as reported by boys with Attention Deficit Hyperactivity Disorder (ADHD) and control students without disabilities, finding that global self-concept was equivalent between the groups. This finding was further replicated by Gresham et al. [22] who found that both students with hyperactivity-impulsivityinattention and conduct problems and students with externalizing and internalizing behaviors reported average levels of self-concept even though peers and teachers reported that these same students were socially rejected.

The phenomenon of elevated self-reported levels of selfconcept has been characterized in the literature as positive illusory bias, or an overly positive view of oneself despite contradictory external indices to contrary [23]. This "overly inflated" view has been found in students with externalizing behavioral manifestations $[21,22]$, as well in students with learning disabilities [24]. A number of theories have been posited as to why students who, by definition, would have low self-concept, yet, self-report high levels of academic and social self-concept, including positive illusory bias serving as a protective factor buffering them from negative effects of social and academic failures [25], or that these students perceive neutral social interactions as being hostile or negative [26].

A recent study by Wei and Marder [27] examined selfconcept trajectories for students with disabilities and how gender and racial differences impacted those trajectories from elementary to high school. Using data from the Special Education Elementary Longitudinal Survey (SEELS) and a novel data analystic approach, Wei and Marder found, overall, that students with disabilities have varying mean levels of self-concept, but similar, descending trajectories across time, indicating the need for educators to assess and target students' attribution beliefs. Interestingly, the study found that students with EBD reported lower levels of social self-concept and self-image compared to students with LD. 
These findings are in contrast to those reported in earlier studies related to positive illusory bias outlined previously.

1.2.2. Sociological Theories and Self-Concept. A growing literature in the mental health, mental illness, and delinquency fields has begun examining practitioner and researcher bias (i.e., adults contradictory external indices) from a sociological perspective [28-31]. These theoretical traditions have been under-utilized in special education research, but may provide a broader framework for understanding the mechanisms impacting students' with EBD self-concept. Ungar [29] found that youth in out-of-home placements, such as foster care and residential care, negotiated their identity development as a resilience to the lack of resources available to them. Problem behaviors maintained a sense of discursive power, or a fluid movement of personal understanding of power constructed and forced upon, that enhanced the individual's resilience to disempowering situations. This sense of identity development as resistance and resilience has also been elaborated upon by Fordham and Ogbu [32] in their ethnographic study of high school students in Washington D.C., finding that minority students develop "fictive kinship", or an oppositional collective identify, against the dominant culture. Similarly, Gooden [33] found that delinquent behaviors brought greater self-esteem and were motivated by affirmation outside normative social behaviors that threaten self-affirmation due to the youth's disempowerment resulting from their SES and minority status. This research points to a potential identity negotiated in response to the stigma of being labeled different [34].

Labeling theory posits that perceived negative societal reactions lead to the development of negative self-concept and sustained levels of delinquent behavior [35, 36]. Labeling theory as an explanatory framework can work to indentify evaluative mechanisms in schools and how schools support those mechanisms, how students react to those evaluations, and the outcomes of student evaluations over time [37]. For students with EBD, labeling theory provides a framework to examine how the process of identification and labeling as EBD impacts their lives, particularly their self-concept. Labeling theory combines both the social interactionist outcomes of being stigmatized and the descriptions of the mechanisms, or the institutionalized hegemonic power structures disciplining bodies exert, impacting the identities of students with EBD.

An outcome of labeling for students is the "self-fulfilling prophecy" [38]. An early study of the self-fulfilling prophecy [39] assessed an entire elementary school using an academic abilities test and then identified $20 \%$ using a random number generator for an experimental condition. The teachers were given a list of students and informed that these students would exhibit unusual intellectual gains during the school year. Results indicated that the "labeled" students performed statistically significantly higher than the control students, suggesting that something was different for the experimental group. Rosenthal and Jacobson posited that the expectations influenced the teachers' behavior, causing them to treat the experimental group differentially therefore positively influencing their test scores.
The self-fulfilling prophecy begins with a false definition of a situation or context that evokes new behaviors that make the original false definition true [37].

Deviance, like EBD, is a social construct; it only exists as a sanctioned label through social agreement of normal behavior. By deviating from accepted typical behavior, students risk identification as a deviant or, in the case of sustained aberrant or antisocial behavior in schools, as a student with EBD. Further complicating the application of labels are the contingencies of race, class, sex, sexual orientation, visibility of a behavior, and who one's friends are. Each of these contingencies can increase the likelihood of identification as a deviant and the self-concept impact that may follow.

As noted previously, labeling theory posits that the deviance label should be associated with negative selfconcept. Further, research has found that low self-esteem is a contributing factor in aggression, poor school achievement, adverse health outcomes, substance abuse, eating disorders, teenage pregnancy, and other concerning behaviors and outcomes [40]. Based on these assumptions and in contradiction to the research findings outlined before for students with externalizing behaviors, students with EBD should be more likely to report negative self-concepts.

1.3. Purpose. This study was designed to explore the selfconcepts of students with EBD as they transition from elementary to middle school and on to high school. Based on the literature review and theoretical framework, the study aims to address the following research questions and explore findings in relation to psychological/educational and sociological theories.

(1) How do students with EBD report their self-concept in elementary school and how does their self-report change as they transition to middle and high school?

(2) Do time-invariant predictor variables impact students' with EBD self-concept?

\section{Method}

To explore the relationship between students' with EBD selfconcept over time and the predictive influence of timeinvariant moderating variables, a secondary data analysis of the Special Education Elementary Longitudinal Study (SEELS) was conducted. SEELS is a national policy study of elementary and middle school students with disabilities mandated by the U.S. Department of Education and developed and implemented by Stanford Research Institute (SRI) International, a U.S.-based nonprofit organization specializing in educational research. SEELS collected data three times over five years (2001-2006) on students, their families, their teachers, and their schools. The SEELS' database has a nationally representative sample of students with disabilities and provides a broad range of information at the student level for analysis. The study utilized a stratified sampling procedure and developed requisite sample weights for analysis and inference of a nationally representative sample. Analyses conducted using the sample weights require 
adjustment to the standard error of the estimate prior to analysis for robust findings in analytic procedures such as those used within this study. This study utilized data from the direct assessment database.

2.1. Participants. The Wave 1 direct assessment database included a weighted sample of 166,802 students with EBD, Wave 2 included 131,010 students with EBD, and Wave 3 included 123,401 students with EBD. Of those students assessed, only 99,155 students with EBD completed all three waves and were included in the analysis. All the students were identified as EBD by their respective school districts and received IEP services. During Wave 1, students ranged in age from 7 to 14 years $(M=10.9)$, during Wave 2, students ranged in age from 8 to 15 years $(M=12.1)$, and during Wave 3, students ranged in age from 10 to 17 years $(M=14.0)$. Seventy-four percent were male $(n=$ $73,440)$ and $25.9 \%$ were female $(n=25,715) ; 62 \%$ were white $(n=61,468), 30.7 \%$ were African-American $(n=$ $30,411), 6.3 \%$ were Hispanic $(n=6,259)$, and $1 \%$ were American Indian/Alaska Native (1016); 43.2\% $(n=42,794)$ of the students' families earned $\$ 25,000$ and under, $29.7 \%$ $(n=29,449)$ earned $\$ 25,001$ to $50,000,19.8 \%(n=19,650)$ earned over $\$ 50,000$, and $7.3 \%(n=7,261)$ did not report an income level; $10.4 \%(n=10,301)$ of the students lived in rural settings, $48.4 \%(47,998)$ of the students lived in suburban settings, $39.5 \%(n=38,016)$ of the students lived in urban settings, and $2.9 \%(n=2,839)$ of the students did not respond to the urbanicity question.

\subsection{Measures}

2.2.1. Dependent Variables. This study utilized data from the direct assessment in the SEELS database. Specific items for the self-concept construct included three aggregate values from an abbreviated version of the Student Self-Concept Scale [41]:

(i) academic self-concept, which included questions such as "I can speak in class when my teacher calls on me",

(ii) social self-concept, which included questions such as "I can make friends easily",

(iii) overall self-concept, which was a unified self-concept value from the rating scale.

Additionally, a measure of friendship and loneliness was culled from a survey developed by Asher et al. [42]. The original survey had 24 items, but 22 of the 24 were control items. Only two questions were retained and used on the direct assessment and included as self-report variables related to the students' self-reported self-concept:

(i) friendship, which asked the question, "I can find a friend when I need one",

(ii) loneliness, which asked the questions, "I am lonely at school".

The individual score for each question for each student was included in the analysis.
2.2.2. Time-Invariant Predictor Variables. Five time-invariant predictor variables were included in the analysis to identify whether or not student characteristics impacted selfconcept:

(i) age, recorded in number of years,

(ii) ethnicity, consisting of four groups: Caucasian, African-American, Hispanic, and Native American,

(iii) gender, recorded as male or female,

(iv) income, consisting of three categories of socioeconomic status (SES): $\$ 25,000$ and under, $\$ 25,001$ to 50,000 , and over $\$ 50,000$,

(v) urbanicity, consisting of three categorical values: rural, suburban, and urban.

2.3. Data Analysis Procedures. The variables were entered into a correlation data matrix, using Pearson's product moment correlation coefficients, containing each variable measured across all three data collection times, and the time invariant variables. In addition to the matrix, the mean and standard deviation for each variable were recorded because these statistics were needed to conduct LGM with AMOS 7.0 [43], a statistical package designed for structural equation modeling. The models were designed in AMOS 7.0, and the data was input into the models. Modeling was conducted in the following stages [44].

2.3.1. Confirmatory Factor Analysis. The initial model fit/confirmatory factor analysis was conducted to confirm the existence of the latent construct self-concept. The confirmatory factor analysis (CFA), or measurement, model was included because it was used in both the LGM and LGM with time-invariant predictors.

2.3.2. Latent Growth Model. The LGM model was conducted to identify intra- and interindividual differences at baseline and rates of growth for the self-concept construct for students with EBD. In addition, the model includes a covariance parameter to identify whether or not baseline values predict rates of growth.

2.3.3. Latent Growth Model with Time-Invariant Predictors. The final model was conducted to identify whether any of the time-invariant variables predicted baseline and/or growth patterns in self-concept construct for students with EBD. Figure 1 provides a description of the hypothesized LGM with time-invariant predictors.

2.3.4. Adjusted Standard Errors. Because the SEELS data collection utilized a stratified random sampling procedure, the weighted estimate standard errors calculated are inaccurate because the procedure assumes a random sample. To correct the standard errors and report robust accurate $P$ values, all standard error values were adjusted using the following formula developed by SRI for SEELS analysis:

$$
\text { Adjusted SE }=\mathrm{SE} * 1.25 \sqrt{\frac{M^{2}+V}{M^{2}}},
$$




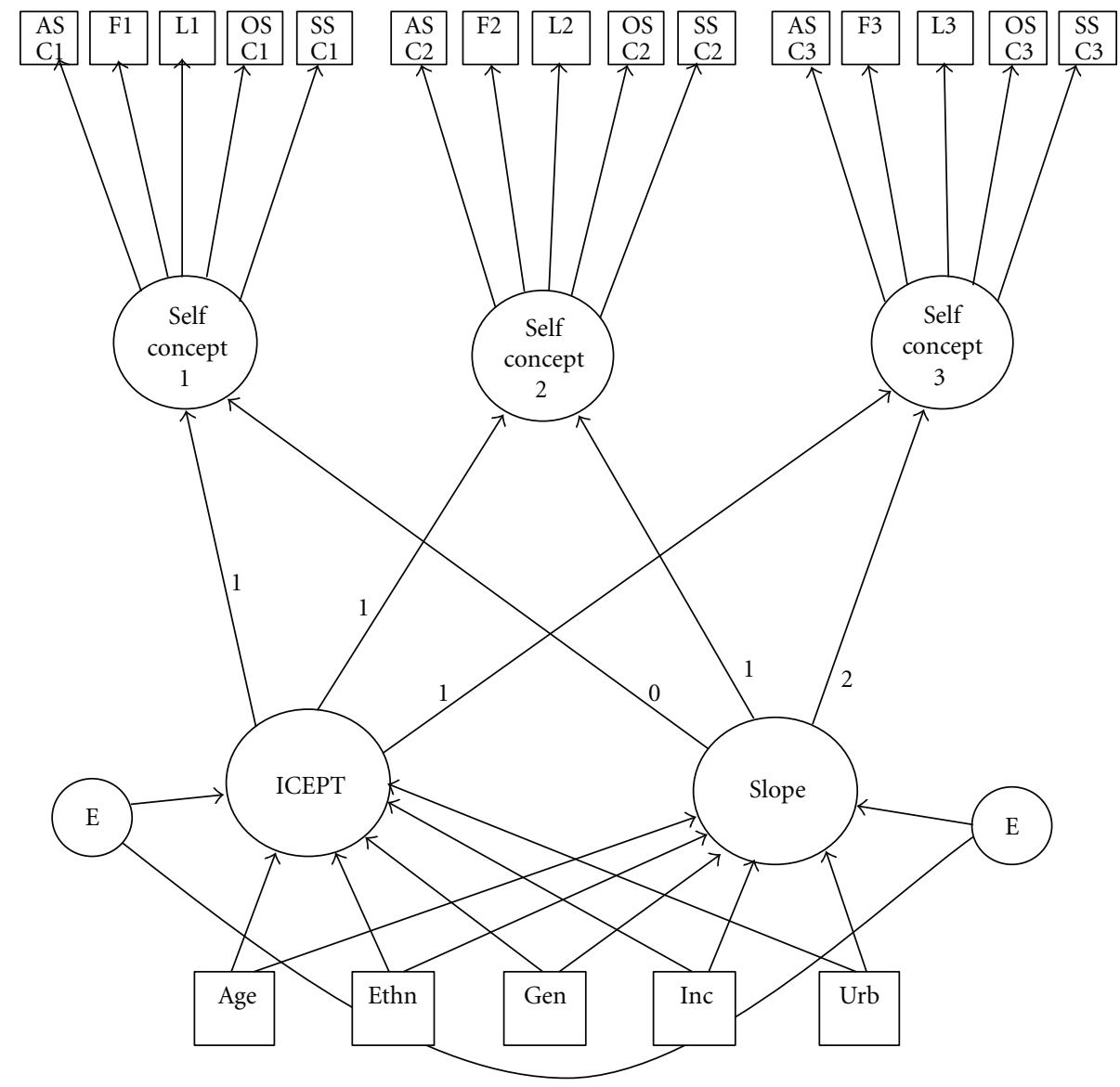

FIGURE 1: Full Hypothesized Latent Growth Model. ASC is academic self-concept, F is friendship, L is loneliness, OSC is overall self-concept, and SSC is social self-concept. Numbers following each variable represent wave, with 1 for Wave 1, 2 for Wave 2, and 3 for Wave 3 . ICEPT is for the intercept, E is for error, Ethn is ethnicity, Gen is gender, Inc is income, and Urb is urbanicity.

where $\mathrm{SE}$ is the calculated standard error, $M$ is the mean of the weights, and $V$ is the variance of the weights.

\section{Results}

The purpose of this study was to identify how students with EBD reported on their self-concept, how that view changed over time as students transitioned from elementary to middle and high school, and what factors contributed to the inter and intra individual self-concept differences. Of note, based on the mean values in Table 1 are the high levels of academic, social, and overall self-confidence. The mean scores are very near the ceiling of the measure (15), indicating that most of the students have very high levels of self-concept and that those levels remain high as the students transition into middle and high school. Although all of the correlations were significant at the $P=.05$ level, the significant correlations were not flagged in the matrix for two reasons: (1) significant correlations were not related to the research questions, and (2) the correlation significant values are a function of the sample size.

The confirmatory factor analysis was developed to empirically verify the latent construct self-concept from the observed dependent variables. The results in Table 2
TABLE 1: Dependent variable mean scores.

\begin{tabular}{lccc}
\hline & Wave 1 & Wave 2 & Wave 3 \\
\hline Academic self-concept & 12.9 & 12.7 & 12.6 \\
Social self-concept & 12.6 & 12.3 & 12.8 \\
Overall self-concept & 13.1 & 13.1 & 13.3 \\
Friendship & 1.7 & 1.6 & 1.6 \\
Loneliness & 2.2 & 2.2 & 2.2 \\
\hline
\end{tabular}

Highest possible score for Academic, Social, and Overall Self-Concept is 15; Friendship and Loneliness scores were 1 for "yes", 2 for "no", and 3 for "sometimes".

identify all observed variables as significantly loading on the latent construct; however, although significant, loneliness had a very low coefficient $(-0.064)$. Hu and Bentler [45] empirically developed a joint criteria model fit for SEM models, including CFA and LGM, necessitating indices values as follows: TLI and CFI $\geq 0.96$, SRMR $\leq 0.09$, and RMSEA $\leq 0.06$. Although the $\chi^{2}$ value is significant (a function of the sample size), the joint criteria are all met, confirming the validity of the model.

Based on the results of the CFA, a latent construct, selfconcept, was confirmed. In this study self-concept operated as a reified construct representing a student's conception of 


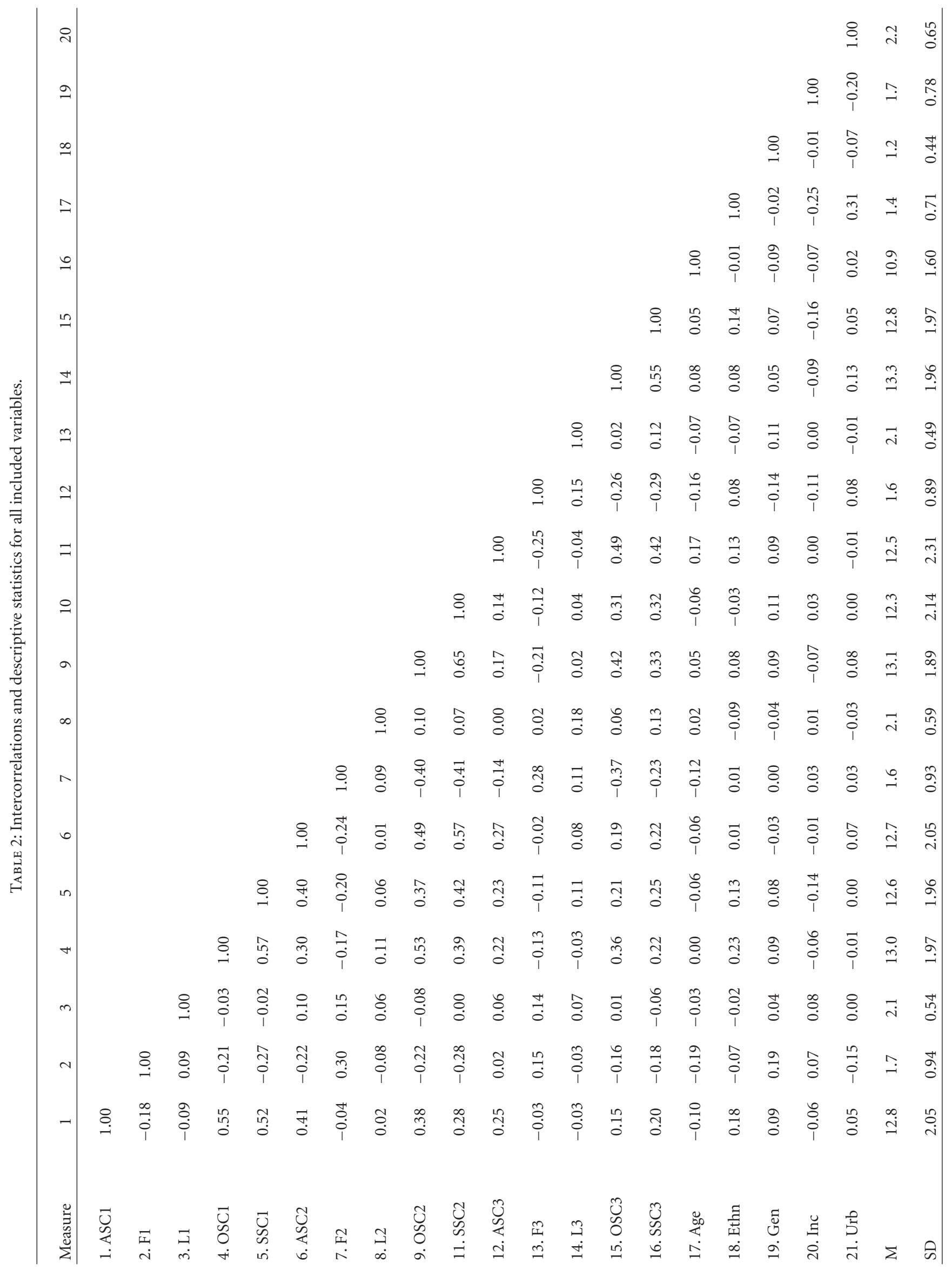


their ability to be successful, both academically and socially, and having the confidence that they can make and sustain a friendship when needed or wanted. In order to test how students vary during the first measurement period (baseline or Wave 1) and how students' self-concepts change, the LGM analysis was conducted.

The LGM results are presented in Table 2. The model fit indices indicate a less than ideal model fit. The $\chi^{2}$ value is significant, again as a function of sample size, but the CFI, TLI, RMSEA, and SRMR all fall short of the joint criteria. The model fit indices indicate the tenuous state of the growth model, potentially resulting from the large sample size; however, the results can still be interpreted [44]. The covariance coefficient between the intercept and slope was both significant and negative, meaning that a student's selfconcept score is significantly related to the student's rate of growth. In this case, because the coefficient is negative, if a student has high self-concept at baseline, their self-concept will decrease .39 for every standard deviation and vice versa for students that start low. The variance coefficients for both the intercept and slope were also significant, meaning that there is significant variability between students at both baseline and in their rates of growth.

The final model, the LGM with time-invariant predictors, results are presented in Table 3 and Figure 2. The model fit indices are less than ideal and could be attenuated via covariance parameters between predictor variables; however, the results are interpreted here because (1) the sample size is influencing the model fit and (2) the researchers accept the results as tenuous and exploratory in nature. All of the predictor variable coefficients were significant at the $P=$ .000 level, indicating that all of variables contribute some level of explanatory value to the model. Because the values are standardized and the $\beta$ is an effect size measure, the results can be interpreted further. Based on this model, the single best predictor for students' baseline score was ethnicity $(\beta=.437)$, while ethnicity $(\beta=-.174)$ and urbanicity $(\beta=-.113)$ were the most influential variables on the slope.

\section{Discussion}

The results of the study suggest an overall positive selfconcept for students with EBD. Although significant variability was evident in the self-reported self-concept of students with EBD in elementary school and as they transition to middle and high school, the mean values for each measurement period were high. These findings support the Positive Illusory Bias theory for students with EBD as noted; Hoza and colleagues [21] and Gresham and colleagues [22] identified patterns of elevated self-concept for students with aggressive behaviors. Although students with externalizing behaviors are more likely to be referred and classified as having EBD within schools $[6,46]$, the educational category, as delineated by the Individuals with Disabilities Education Act (IDEA), is biased toward internalizing behaviors with four of the five eligibility criteria often associated with internalizing behaviors [47]. No variable was available to delineate the topography of behaviors exhbited by students with EBD in this study; therefore no conclusions can or should be drawn other than the mean levels of self-concept were high, based on the range of scores, for this population across the grade span.

The findings of this study hint that the sociological theories of deviance may not hold true for this population. Labeling theory suggests that these students should have internalized their deviance, particularly because these students have exhibited consistent patterns of problematic behavior, and have been identified for special education services. The stigma of being a special education student, particularly one with emotional disturbance, should have had a negative impact on the students' cognitive assessment of their social and academic competence, yet, the results of this nationally representative sample suggest otherwise. These findings hint at a mismatch between theory and empirical support, throwing doubt on labeling theory as a potential explanatory framework for student's with EBD selfconcept.

Perhaps most interesting is the difference in findings between this study and Wei and Marder's [27] findings as both used the same database. There may be a number of reasons for these differences. First, Wei and Marder developed their own measures of self-concept from the 30 available questions from the Student Self-Concept Scale [41] while this study utilized the aggregate single domain score from the database. Second, their analyses were based on a single question as the dependent variable within their models, while this study used a theory-based structural equation model approach with a latent construct as the dependent measure that included additional questions related to loneliness and friendship. Lastly, Wei and Marder found a significant decreasing slope from elementary to high school. This slope was based on age as the time variable. This study used wave as the time variable. The key difference is that there were variations of sample size within each age category used in Wei and Marder's study that may have impacted the overall slope values or were washed out in the LGM analysis used in this study. For example, there were only 93 16-17-year-old students with EBD total that answered the social self-concept questions. To control for this issue, the model used in this study included "age" as a moderating variable and found that age impacted variability. This suggests that, at a mean level, students reported high levels of self-concept. However, based on Wei and Marder, those levels statistically significantly decrease as students get older, particularly in their middle to late teen years.

The analysis of the moderating time-invariant predictor variables intimates a few important findings. Among the most important was the role ethnicity potentially plays in self-reported self-concept of students with EBD. Based on the $\beta$ intercept for ethnicity in elementary school, white students with EBD appeared to have lower self-concept than minority students, particularly African-American students based on the hypothesized model. However, as these students transitioned from elementary to middle and high schools, the self-concept of white students increased, while the self-concept of minority students statistically significantly decreased. Here, the sociological theories may be helpful to further explore these trends. One possible explanation 
TABLE 3: Confirmatory factor analysis and latent growth models.

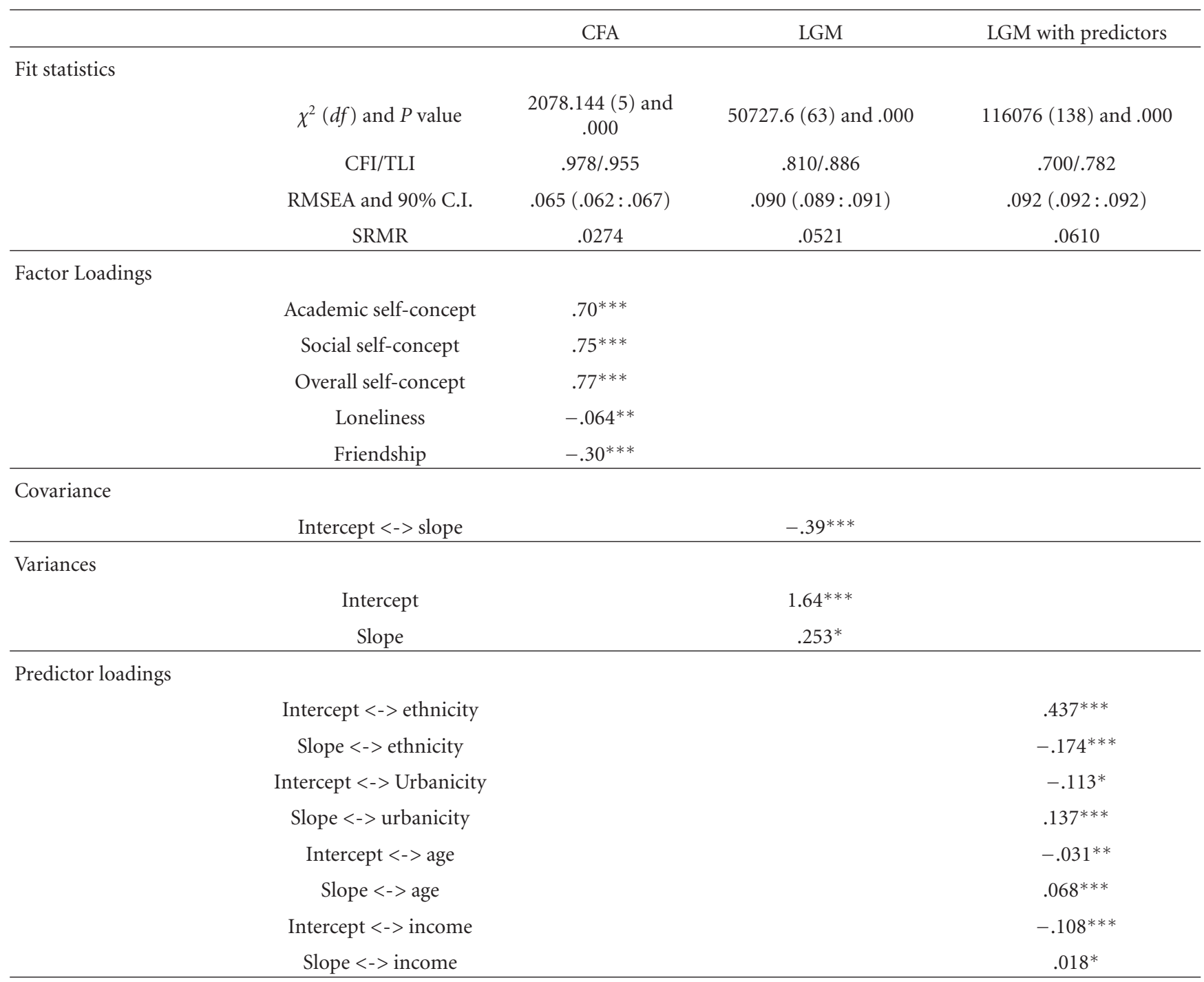

${ }^{*} P<.05,{ }^{* *} P<.01,{ }^{* * *} P<.000$.

for the decreasing trend in the model is the contingencies Rist [37] highlighted that further complicate the labeling process. Minority students with EBD are doubly "marked", and, as they transition to middle school, the surveillance of behavior by school personnel is more intense for minority students [32]. Because of their ethnicity, minority students may be differentially treated (e.g., placed in more restrictive environments) when compared to white students with EBD [48]. Although it was surprising that SES was not a strong predictor of variability in the slope, the influence of urbanicity tentatively supports Fordham and Ogbu's [32] findings. The positive coefficient value suggests that an increase in self-concept is paired with an increase in urbanicity; students in urban settings are more likely to have higher self-concepts based on the model. In contrast, students in rural settings typically attend schools with less students, possibly increasing the likelihood that students with EBD are more visible, particularly minority students with EBD. Anonymity may be more difficult in rural schools and the students' peers may be more likely to recognize students as special education students, thereby creating opportunities for directed differential treatment. Urban schools tend to be much larger and may provide opportunities for anonymity. Additionally, urban schools typically have higher percentages of minority students, allowing for development of collective identities or "fictive kinships" [32], which may provide a better frame for understanding and examining differential patterns of self-reported self-concept. Consistent across all of the theories is the role peers with similar behavior patterns play in supporting each other. Urban schools with more minority students will be more likely to support each other than minority students in rural schools. However, as noted previously, the growth model fit indices were less than ideal; therefore all findings should be interpreted as tenuous and exploratory.

4.1. Implications. The results of this study, as well as previous research, have implications for educators working 


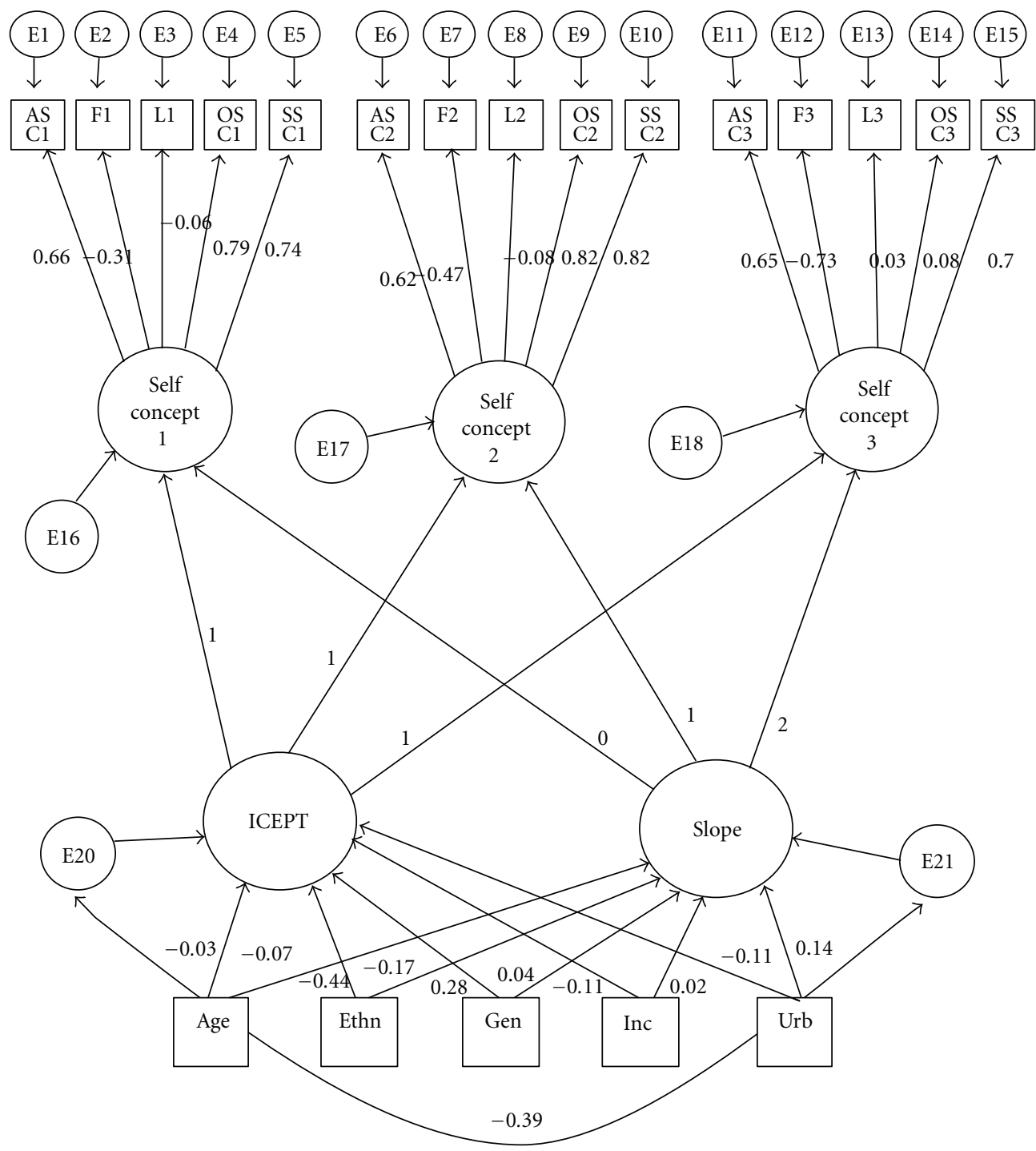

FIGURE 2: Full latent growth model with time invariant predictors. All variable labels are the same as those in Figure 1.

with students with EBD. First, it is clear that there is no universal pattern of self-concept for students with EBD as a heterogeneous group; there is significant variability in how these students self-report in regards to their social, academic, and overall self-concept. By definition, these students exhibit behavioral and academic difficulties, but educators should not assume that students with EBD recognize or internalize those deficits. Interventions and programs should be tailored to individual needs of students based on assessment of their social and emotional needs. Along these lines, teacher preparation programs should provide training in assessing and intervening when students exhibit either low selfconcept or positive illusory bias. This issue was raised by Pavri and Hegwer-DiVita [49], who found that the majority of teachers reported being unprepared in supporting the emotional needs of their students.

Second, educators should not make causal interpretations of self-concept and behavioral performance. Students with EBD may be socially isolated and unable to make or sustain friendships in school, but they may perceive that they have the skills to be socially successful. Whether this self-perception of skill serves as a protective factor [25] against external interpretations for those exhibiting positive illusory bias or is related to a misunderstanding of social cues remains an area in need of further research. The key is that educators should work with these students to develop goals and strategies without challenging their elevated levels of self-concept. Baumeister et al. [50] hypothesized that aggressive behavior exhibited by some students was a reaction to external evaluations of their unrealistically high self-esteem. Therefore educators should be cautious and caring, not calling out students and pointing to their positive illusory bias, but instead working with students on the development of prosocial skills. As students increase successful social interactions using appropriate social skills, their behavior performance may be more aligned with their selfperceptions. Regardless, educators should focus on directly teaching social skills to increase successful social interactions 
for these students, including providing opportunities for practice, and avoid making assumptions about what the students can or cannot do.

4.2. Limitations. This study used a nationally representative sample of students with EBD; however a number of limitations warrant highlighting. Although the analysis used adjusted standard errors, the results represent approximations to the population. Like all samples, generalization without further replication should be noted as tenuous and exploratory. Additional issues with the dataset include the observed variables. Although the self-concept scale was as a standardized measure, and asked questions of the students to indicate their cognitive appraisal, measures of self-esteem would provide further descriptive quality to the findings. Additionally, the self-concept measure was adapted for use in the study; therefore direct comparisons between the results from the database and the standardization sample of the original measure are not possible. The loneliness and friendship scores were problematic in that they represented just one question on a 3-point Likert scale, which contributed to their lower factor coefficient scores. Further, the modelfit indices indicate that the model was not ideal. This may have been due to a number of factors, but the interpretation of the results should be tempered as a result. Further research is warranted in order to examine longitudinal trajectories of self-concept for students with EBD.

\section{Conclusions}

The results of this study shed light on the self-concept of students with EBD. First, the evidence suggests that students with EBD have high, positive levels of self-concept. This finding runs counter to the assumptions about labels and their impact on self-concept. Second, although there is significant variability in self-concept among these students, student scores in elementary can predict their self-concept in middle and high school. Lastly, ethnicity and urbanicty may be good predictors of self-concept for students with EBD.

Further research is necessary to confirm the results of this study. One area in need of further research is the process of how these students conceive of their self-concept as they transition to middle school. This study provided a broad assessment, but qualitative studies examining how these students report to view themselves and their competence would contribute greatly to a deeper understanding of the phenomenon. Additional research should also be targeted at working with these students to utilize their heightened selfconcept to increase their social and academic performance. Although the study found high, positive self-concept, we know that the behavioral performance of these students is lacking.

This study set out to explore how elementary students with EBD reported their self-concept, and how that changed as they transitioned to middle school and high school. The findings shed light on how these students see themselves, the results of which should help educators identify intervention methods to increase social and academic performance. Taken together, the results further our understanding of these students and challenge our assumptions about how they view themselves.

\section{Acknowledgment}

Preparation of this paper was supported in part by a grant from the Institute for Education Sciences, U.S. Department of Education (R324B080007).

\section{References}

[1] J. McLeskey, E. Landers, P. Williamson, and D. Hoppey, "Are we moving toward educating students with disabilities in less restrictive environments," Journal of Special Education. In press.

[2] R. Bradley, J. Doolittle, and R. Bartolotta, "Building on the data and adding to the discussion: the experiences and outcomes of students with emotional disturbance," Journal of Behavioral Education, vol. 17, no. 1, pp. 4-23, 2008.

[3] M. Montague, C. Enders, W. Cavendish, and M. Castro, "Academic and behavioral trajectories for at-risk adolescents in urban schools," Behavioral Disorders, vol. 36, no. 2, pp. 141156, 2011.

[4] R. L. Simpson, R. L. Peterson, and C. R. Smith, "Critical educational program components for students with emotional and behavioral disorders: scienec, policy, and practice," Remedial and Special Educaion, vol. 32, no. 3, pp. 230-242, 2011.

[5] R. B. Rutherford, M. M. Quinn, and S. R. Mathur, Handbook of Research in Emotional and Behavioral Disorders, The Guildford Press, New York, NY, USA, 2004.

[6] J. M. Kauffman and T. J. Landrum, Characteristics of Emotional and Behavioral Disroders of Children and Youth, Prentice Hall, Upper Saddle River, NJ, USA, 9th edition, 2009.

[7] B. M. Byrne, Meausreing Self-Concept Through the Lifespan: Issue and Implementation, American Psychological Association, Washington, DC, USA, 1996.

[8] P. Eggen and D. Kauchak, Educational Psychology: Windows on Classrooms, Merrill, Upper Saddle River, NJ, USA, 4th edition, 1999.

[9] H. W. Marsh and R. G. Craven, "Reciprocal effects of selfconcept and performance from a multidimensional perspective: beyond seductive pleasure and unidimensional perspectives," Perspectives on Psychological Science, vol. 1, pp. 133-163, 2006.

[10] R. J. Shavelson, J. J. Huber, G. C. Stanton et al., "Self-concept: validation of construct interpretation," Review of Educational Research, vol. 46, pp. 407-441, 1976.

[11] V. Gecas, "The self-concept," Annual Review of Sociology, vol. 8, no. 1, pp. 1-33, 1982.

[12] S. Epstein, "The self-concept revisited or a theory of a theory," The American Psychologist, vol. 28, no. 5, pp. 404-416, 1973.

[13] L. E. Wells and G. Maxwell, Self-Esteem: Its Conceptualization and Measurement, Beverley Hills, San Diego, Calif, USA, 1976.

[14] V. Gecas and M. L. Schwalbe, "Beyond the looking-glass self: social structure and efficacy-based self-esteem," Social Psychology Quarterly, vol. 46, no. 2, pp. 77-88, 1983.

[15] C. Huang, "Self-concept and academic acheivement: a metaanalysis of longitudinal relations," Journal of School Psychology, vol. 49, no. 5, pp. 505-528, 2011.

[16] F. M. Gresham and D. L. MacMillan, "Social competence and affective characteristics of students with mild disabilities," 
Review of Educational Research, vol. 67, no. 4, pp. 377-415, 1997.

[17] G. Bear and K. Minke, "Positive bias in maintenance of selfworth among children with LD," Learning Disability Quarterly, vol. 19, no. 1, pp. 23-32, 1996.

[18] A. Clever, G. Bear, and J. Juvonen, "Discrepencies between comptence and importance in self-perceptions of childen in integrated classrooms," Journal of Special Education, vol. 26, no. 2, pp. 125-138, 1992.

[19] K. Kavale and C. Nye, "Parameters of learning disabilities in achievement, linguistics, neuropsychological, and social/behavioral domains," Journal of Special Education, vol. 19, no. 4, pp. 443-458, 1989.

[20] W. J. Hagborg, "Self-concept and middle school students with learning dsiabilities: a comparison of scholastic competence subgroups," Learning Disbility Quarterly, vol. 19, no. 2, pp. 117-126, 1996.

[21] B. Hoza, W. Pelham, R. Milich, D. Pillow, and K. McBride, "The self-perceptions and attributions of attention deficit hyperactivity disordered and nonreferred boys," Journal of Abnormal Child Psychology, vol. 21, no. 3, pp. 271-286, 1993.

[22] F. M. Gresham, D. L. MacMillan, K. M. Bocian, S. L. Ward, and S. R. Forness, "Comorbidity of hyperactivity-impulsivityinattention and conduct problems: risk factors in social, affective, and academic domains," Journal of Abnormal Child Psychology, vol. 26, no. 5, pp. 393-406, 1998.

[23] F. M. Gresham, K. L. Lane, D. L. MacMillan, K. M. Bocian, and S. L. Ward, "Effects of postive and negative illusory biases: comparisons across social and academic self-concept domains," Journal of School Psychology, vol. 38, no. 2, pp. 151$175,2000$.

[24] G. G. Bear, K. M. Minke, and M. A. Manning, "Self-concept of students with learning disabilities: a meta-analysis," School Psychology Review, vol. 31, no. 3, pp. 405-427, 2002.

[25] M. B. Diener and R. Milich, "Effects of positive feedback on the social interactions of boys with attention deficit hyperactivity disorder: a test of the self-protective hypothesis," Journal of Clinical Child Psychology, vol. 26, no. 3, pp. 256-265, 1997.

[26] K. A. Dodge, R. R. Murphy, and K. Buchsbaum, "The assessment of intention-cue detection skills in children: implications for developmental psychopathology," Child development, vol. 55, no. 1, pp. 163-173, 1984.

[27] X. Wei and C. Marder, "Self-concept development of students with disabilities: disability category, gender, and racial differences from early elementary to high school," Remedial and Special Education. In press.

[28] D. Gregson, "Normally very abnormal: a perspective on youth at risk," Journal of Child and Youth Care, vol. 9, no. 2, pp. 3141, 1994.

[29] M. Ungar, "The social construction of resilience among "problem" youth in out-of-home placement: a study of healthenhancing deviance," Child and Youth Care Forum, vol. 30, no. 3, pp. 137-154, 2001.

[30] M. Ungar and E. Teram, "Drifting toward mental health: highrisk adolescents and the process of empowerment," Youth and Society, vol. 32, no. 2, pp. 228-252, 2000.

[31] L. Weis and M. Fine, Eds., Beyond Silenced Coices: Class, Race, and Gender in United States Schools, State Univeristy of New York Press, New York, NY, USA, 1993.

[32] S. Fordham and J. U. Ogbu, "Black students' school success: coping with the "burden of 'acting white'"', The Urban Review, vol. 18 , no. 3, pp. 176-206, 1986.
[33] M. P. Gooden, When juvenile deliquency enhances the selfconcept: the role of race and academic performance, Ph.D.dissertation, The Ohio State University, Columbus, ohio, USA, 1997.

[34] E. Goffman, Stigma: Notes on the Management of Spoiled Identity, Simon \& Schuster, Inc., New York, NY, USA, 1963.

[35] M. S. Adams, C. T. Robertson, P. Gray-Ray, and M. C. Ray, "Labeling and delinquency," Adolescence, vol. 38, no. 149, pp. 171-186, 2003.

[36] H. S. Becker, Outsiders: Studies in the Sociology of Deviance, Free Press, New York, NY, USA, 1963.

[37] R. C. Rist, "Student social class and teacher expectations: the self-fulfilling prophecy in Ghetto education," Harvard Educational Review, vol. 70, no. 3, pp. 266-301, 2000.

[38] R. Rosenthal and L. Jacobson, Pygmalion in the Classroom, Holt, Rinehart, and Winston, New York, NY, USA, 1968.

[39] R. Rosenthal and L. Jacobson, "Teachers' expectancies: determinants of pupils' IQ gains," Psychological Reports, vol. 19, no. 1, pp. 115-118, 1966.

[40] J. Crocker and B. Major, "Social stigma and self-esteem: the self-protective properties of stigma," Psychological Review, vol. 96, no. 4, pp. 608-630, 1989.

[41] F. M. Gresham and S. N. Elliot, Student Self Concept Scale (SSCS), American Guidance Services, Inc., Circle Pines, Minn, USA, 1990.

[42] S. R. Asher, S. Hymel, and P. D. Renshaw, "Loneliness in children," Child Development, vol. 55, no. 4, pp. 1456-1464, 1984.

[43] J. L. Arbuckle, Amos 7.0 User's Guide, SPSS, Chicago, Ill, USA, 2006.

[44] R. B. Kline, Principles and Practice of Structural Equation Modeling, Guilford Press, New York, NY, USA, 2nd edition, 2005.

[45] L. Hu and P. M. Bentler, "Cutoff criteria for fit indexes in covariance structure analysis: conventional criteria versus new alternatives," Structural Equation Modeling, vol. 6, no. 1, pp. $1-55,1999$.

[46] F. M. Gresham, K. L. Lane, D. L. MacMillan, and K. M. Bocian, "Social and academic profiles of externalizing and internalizing groups: risk factors for emotional and behavioral disorders," Behavioral Disorders, vol. 24, no. 3, pp. 231-245, 1999.

[47] S. R. Forness and J. Knitzer, "A new proposed definition and terminology to replace "serious emotional disturbance" in individuals with disabilities act," School Psychology Review, vol. 21, no. 1, pp. 12-21, 1992.

[48] T. M. Eitle, "Special education or racial segregation: understanding variation in the representation of black students in educable mentally handicapped programs," Sociological Quarterly, vol. 43, no. 4, pp. 575-605, 2002.

[49] S. Pavri and M. Hegwer-DiVita, "Meeting the social and emotional needs of students with disabilities: the special educators' perspective," Reading \& Writing Qaurterly, vol. 22, pp. 139-153, 2006.

[50] R. Baumeister, L. Smart, and J. Boden, "Relation of threatened egotism to violence and aggression: the dark side of high selfesteem," Psychological Review, vol. 103, no. 1, pp. 5-33, 1996. 


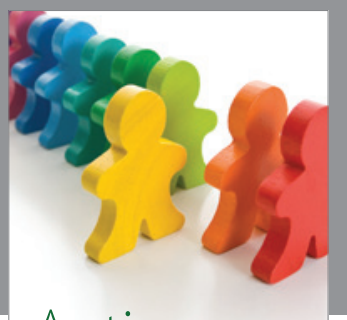

Autism

Research and Treatment
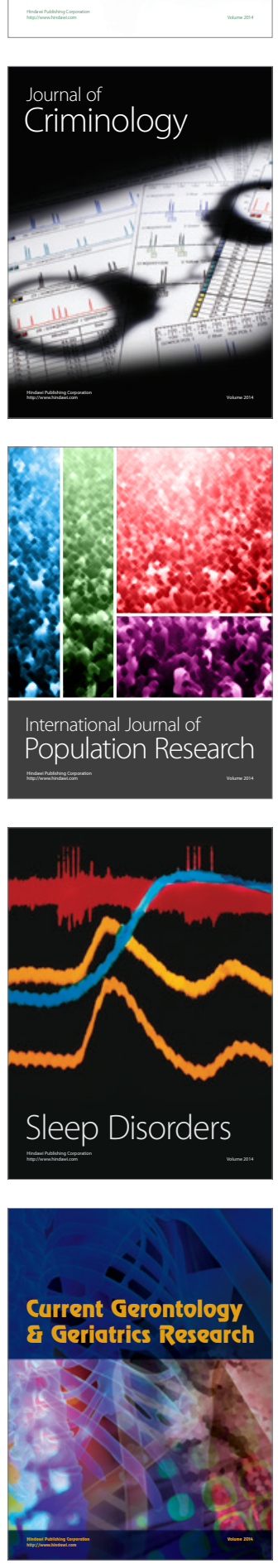
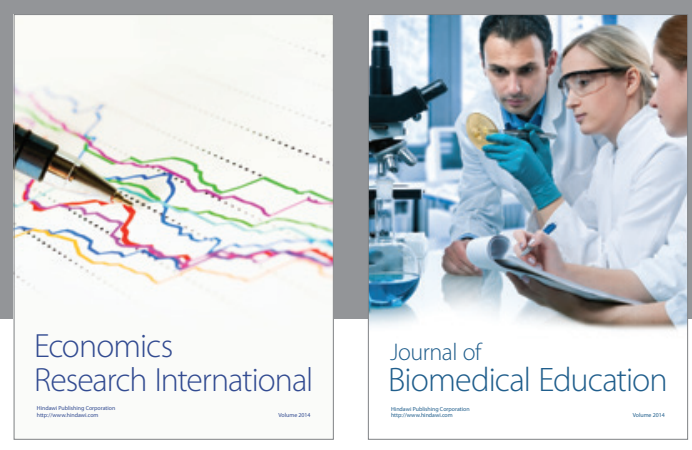

Journal of

Biomedical Education

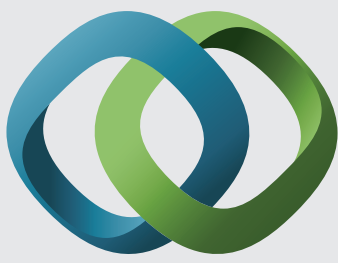

\section{Hindawi}

Submit your manuscripts at

http://www.hindawi.com
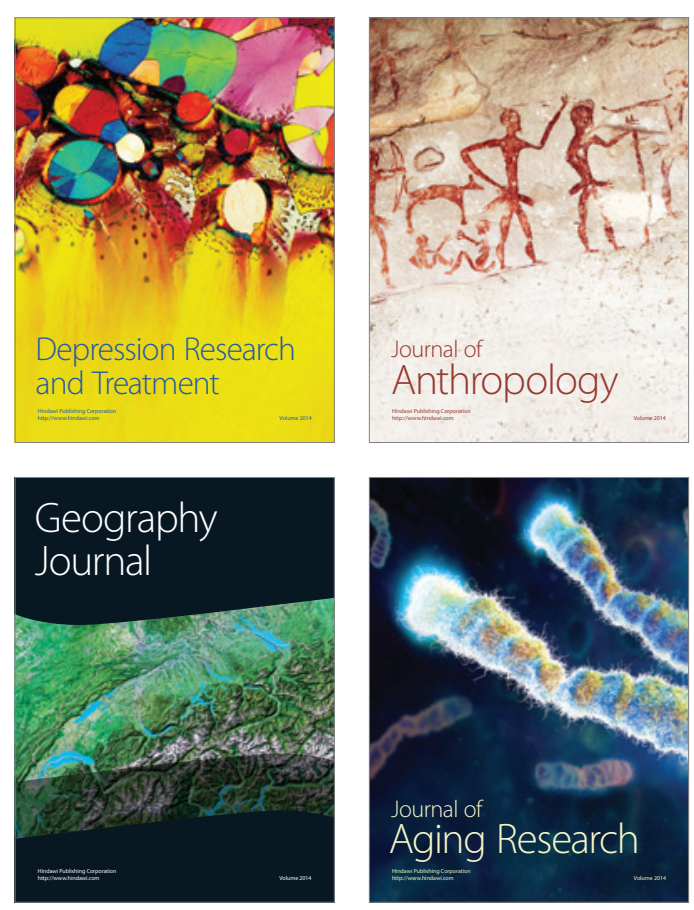

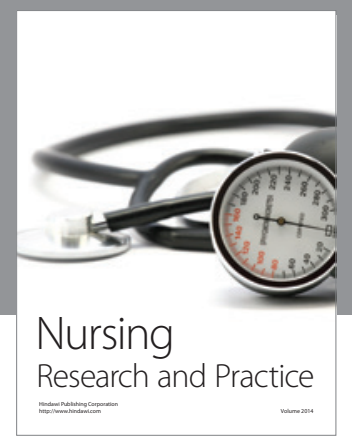

Nursing

Research and Practice

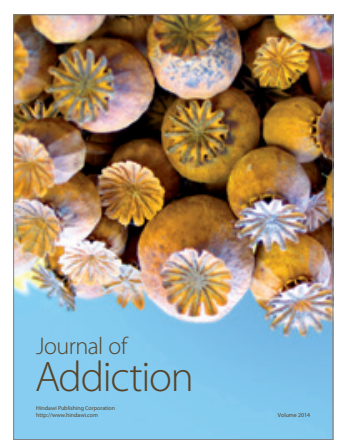

Child Development

Research

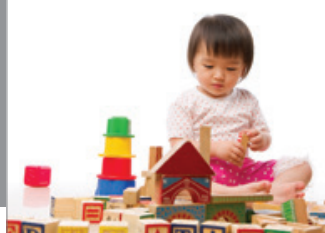

迥
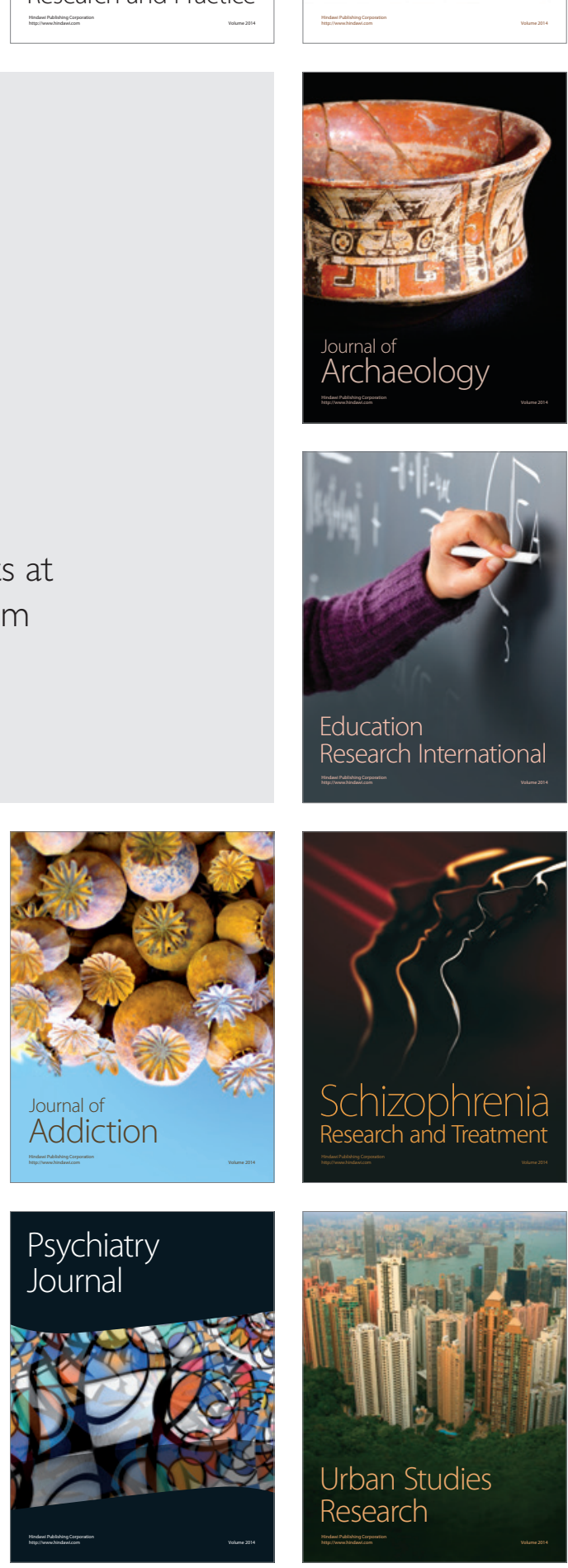